\title{
"FALA QUE EU TE ESCUTO": UM ESTUDO SOBRE O TELEVANGELISMO E A IGREJA UNIVERSAL DO REINO DE DEUS (IURD) NAS CIÊNCIAS DA RELIGIÃO
}

\author{
João Afonso dos Santos L. Pantoja ${ }^{1}$ \\ Kátia Mendonça ${ }^{2}$
}

\begin{abstract}
RESUMO
Atualmente, devido ao advento das mudanças sociais, se evidencia cada vez mais em destaque o avanço tecnológico. Com isso, às denominações religiosas vem utilizando mecanismos de expansão de suas crenças e no Brasil esse fenômeno também vem se enraizando, principalmente nos meios de comunicação. As emissoras de televisão são um dos veículos imediatos e eficazes para a expansão midiática da fé, fenômeno conhecido como Televangelismo. A Igreja Universal do Reino de Deus (IURD) vem se destacando através dos recursos televangélico, entre eles o programa "Fala que Eu Te Escuto" que é um dos responsáveis pelo crescimento de sua denominação. Por fim, a partir de uma abordagem hermenêutica, que contou com análise de quatro programas entre os meses de outubro e novembro de 2017. Entende-se que, com o auxílio do seu programa televangélico, a IURD constitui um elemento indissociável na difusão da sua fé, assim como reforça os dogmas aos já convertidos.
\end{abstract}

Palavras-chave: IURD. Midiatização. Neopentecostal. Televangelismo.

\begin{abstract}
Currently, due to the advent of social changes, technological advancement is increasingly highlighted. As a result, religious denominations have been using mechanisms to expand their beliefs and in Brazil this phenomenon has also taken root, especially in the media. Television stations are one of the immediate and effective vehicles for the media expansion of the faith, a phenomenon known as Televangelism. The Universal Church of the Kingdom of God (IURD) has been standing out through televangelical resources, among them the program "Fala que Eu Escuta" that speaks for one of the responsible for the growth of its denomination. Finally, based on a hermeneutic approach, which included the analysis of four programs between the months of October and November 2017. It is understood that, with the help of its televangelical program, IURD constitutes an inseparable element in the diffusion of its faith, as well as reinforcing dogmas to those already converted.
\end{abstract}

Keyword: IURD. Miatization. Neo-pentecostal. Televangelism.

Submetido em: 18.03 .2020

Aprovado em: 17.04 .2020

\footnotetext{
1 Mestrando no Programa de Pós-Graduação em Ciências da Religião (PPGCR/UEPA). E-mail: joaoafonso979@gmail.com

${ }_{2}^{2}$ Docente no Programa de Pós-Graduação em Ciências da Religião PPGCR/UEPA.
} 


\title{
INTRODUÇÃO
}

A mídia hodierna é hoje um dos principais meios de construção de comunicação que existe, de modo que ela é utilizada de inúmeras formas, por se tratar de um mecanismo informacional extremamente eficiente. Assim, a maneira como mensagem é passada e tão importante como a mensagem transmitida, pois sem o meio, seria impossível transmitir a mensagem. Sob essa ótica, a televisão desempenha um papel gigantesco na medida que sua mensagem é capaz de alcançar distantes lugares, como foi expresso, pelo conceito de meio e a mensagem de Marshall McLuhan:

\begin{abstract}
Este fato, característico de todos os veículos, significa que o "conteúdo" de qualquer meio ou veículo é sempre um outro meio ou veículo. O conteúdo da escrita é a fala, assim como a palavra escrita é o conteúdo da imprensa e a palavra impressa é o conteúdo do telégrafo. Se alguém perguntar, "Qual é o conteúdo da fala?", necessário se torna dizer: "É um processo de pensamento, real, não verbal em si mesmo." [...] Pois a "mensagem" de qualquer meio ou tecnologia é a mudança de escala, cadência ou padrão que esse meio ou tecnologia introduz nas coisas humanas. (MCLUHAN, 2007, p. 22)
\end{abstract}

A utilidade da televisão no campo religioso se expande de acordo com o interesse de cada vertente. Nesse sentido, a religião analisada é a denominação cristã neopentecostal, cujo nome é Igreja Universal do Reino de Deus (IURD), que também desfruta do fenômeno de midiatização da fé, estratégia conhecida como Televangelismo.

O objetivo desse artigo é buscar se aproximar da compreensão desse fenômeno que advêm de várias transformações estratégicas que têm culminado na aceitação dessa nova proposta de evangelização "iurdiana" para com seus telespectadores, através do programa exibido pelo canal Record TV "Fala que Eu Te Escuto", transmitido de segunda a sábado as 01:15 da madrugada, e consecutivamente promovendo o crescimento da vertente IURD.

Para o desenvolvimento deste artigo foram utilizados vários livros, artigos, teses que contribuíram para a construção e articulação das ideias presentes no mesmo, além de fortalecer a análise de alguns programas exibidos. Nessa perspectiva, o artigo encontra-se dividido em três partes: a primeira está relacionada a noções iniciais sobre midiatização e teologia neopentecostal; a segunda procura discorrer sobre a denominação IURD, as práticas do Televangelismo e sua relação com sua ideologia e as temáticas sociais discutidas no programa "Fala que Eu Te Escuto"; e a terceira estabelece a relação entre a forma de evangelização contida no programa, destacando os fatores que promovem a aceitação dos telespectadores em relação as suas convicções religiosas. 


\section{MIDIATIZAÇÃO E TEOLOGIA NEOPENTECOSTAL}

A sociedade vivencia novas perspectivas no cenário global, em todas as camadas sociais, proporcionando uma série de mudanças em todos os contextos. Para Fairclough (2006), não é apenas uma única causa que provoca as mudanças sociais, pois, é primordial entender que essas mudanças ocorrem, a partir de intercâmbios entre fatores e causas. Entre estes estão os eventos presentes no meio social como na sua organização, na sua estrutura, nas suas práticas, nas línguas, nos textos e nos discursos.

Nesse segmento, encontra-se o âmbito religioso brasileiro, estreitamento relacionado à utilização dos recursos midiáticos pelas denominações cristãs. Segundo Sgorla (2009), a midiatização pode ser compreendida como o conjunto de relações que se estabelecem entre as tecnologias de mídia, os campos e os indivíduos. De acordo com o sociólogo Sodré (2002, p. 21 apud Sgorla, 2009, p. 62), a midiatização é entendida como sendo as mediações que se realizam no âmbito social e que tem como foco o processo de comunicação a partir de um tipo particular de interação, que pode ser denominado de "tecno-interação". Ou seja, a partir da difusão de novas tecnologias, como o rádio, televisão e internet, passa haver relações sociais mediadas por protocolos que se sustenta na lógica midiática. Assim, “[...] a comunicação acontece por meio de fluxos, os quais se desprendem novos e infinitos significados e sentidos que se configuram no feixe de interseção entre tecnologia, indivíduo e estratégia" (SGORLA, $2009, \mathrm{p}, 05)$

O processo midiático - práticas de comunicação referentes ao campo da mídia, sua linguagem e dispositivos - se desenvolve a partir de elementos específicos que conferem um caráter especial, que são: tecnologia, discurso e os aspectos sociais. A tecnologia usada pela mídia possui papel importante porque é através dela que se passa a ter a interação simbólica e novas percepções da realidade, assumido dessa forma, papel de referência. Assim, em posse destes elementos, a mídia estabelece a sua percepção de realidade, dos sentidos atribuídos a vida social através do que é dito e visto. A midiatização proporciona modificações no individuo, atualizando e planificando sua postura em relação ao mundo que o circunda. Nessa perspectiva, conforme Verón (2001, p. 15 apud Sgorla, 2009, p. 63) "uma sociedade em vias de midiatização é aquela onde o funcionamento das instituições, das práticas, dos conflitos, das culturas, começa a estruturar-se em relação direta com a existência das mídias”. Logo, a mídia passa a configurar as relações estabelecidas em sociedade, "a partir de uma temporalidade, espacialidade, estética e ideologia singular" (Sgorla, 2009, p. 63). 
O campo da mídia, em sua totalidade também é visto como um meio eficiente para a propagação do fenômeno da globalização. Em contrapartida, esse campo da mídia está sob grande influência dos mais diversos interesses, evidenciando-se no Brasil as emissoras de televisão entrelaçadas a crenças religiosas, predominantemente cristãs, no caso aqui analisada, a igreja Universal do Reino de Deus onde seus preceitos são impostos por inúmeros métodos.

Para compreender o universo da IURD, destacam-se inicialmente algumas características da igreja. Fundada no ano de 1977, na zona norte do Rio de Janeiro, por Edir Macedo Bezerra, a igreja Universal do Reino de Deus cresceu estrondosamente, reunindo adeptos não só Brasil, mais em outros cantos do globo, e este crescimento da IURD muito se justifica pelo fato de estar inserida nos chamados movimentos neopentecostais que tiveram grande ascensão nos anos 70. Tradicionalmente, os movimentos pentecostais são categorizados a partir de três fases ou ondas como ficou conhecida a definição de Paul Freston:

\begin{abstract}
O pentecostalismo brasileiro pode ser compreendido como a história das três ondas de implantação de igrejas. A primeira que é a década de 1910, com a chegada da Congregação Cristã (1910) e da Assembleia de Deus (1911). (...) A segunda onda pentecostal é dos anos 50 e início de 60, na qual o campo pentecostal se fragmenta, a relação coma sociedade se dinamiza e três grandes grupos (em meio a dezenas de menores) surgem: a Quadrangular (1951), Brasil Para Cristo (1955) e Deus é Amor (1962). O contexto dessa pulverização é paulista. A terceira onda começa no final dos anos 70 e ganha força nos 80. Suas principais representantes são a Igreja Universal do Reino de Deus (1977) e a Igreja Internacional da Graça de Deus (1980) (FRESTON,1994, p. 70)
\end{abstract}

Está expansão pode ser explicada por atualizações inovadoras no pensamento neopentecostal que provocaram mudanças nos posicionamentos teológicos, litúrgicos e éticos, em outras palavras "[...] uma forte e eficiente racionalização: organização do dízimo, instituição de uma hierarquia e utilização dos meios de comunicação, da televisão em particular. [...]. São organizações que nascem institucionalizadas, invocam na linguagem litúrgica, na inserção social e participação política" (PASSOS, 2005, p, 93-4).

E a principal razão disso está no fato do neopentecostalismo praticado por essa denominação religiosa estar preocupado não só com a vida espiritual, mas também com a vida terrena, como conceitua Silva (1995):

Promessas de salvação instantâneas, intimidade com o dinheiro, tolerância em relação aos costumes dos fiéis, organização empresarial sofisticada, exploração dos meios de comunicação de massa e técnicas de persuasão enérgicas fazem dos neoevangélico o McDonald's da religião contemporânea. (p. 14) 
Outro fator que sustenta a IURD está em sua doutrina, alicerçada no combate incansável contra os "demônios" os quais são responsáveis pelo caos vivenciado no planeta como doenças, catástrofes, acidentes, crimes, entre tantas outras crises alarmantes. Há também a teologia da prosperidade, na qual o Bispo Edir Macedo se inspira nos pastores norte-americanos quando prega a libertação de maldições através de doações para Igreja $10 \%$ do que recebe, para que assim as forças demoníacas não se apossem de seus bens.

\section{O TELEVANGELISMO: O FENÔMENO DE MIDIATIZAÇÃO DA FÉ}

Diante das concepções sobre a midiatização e todo o seu processo enfatizado no campo social, logo se destaca que essa prática está enraizada no universo cristão, principalmente nas igrejas protestantes de caráter neopentecostal. Esse processo é essencial para as entidades religiosas na contemporaneidade como instrumento de expansão da sua fé, com o objetivo de atrair fiéis através de programas de televisão. A “midiatização da fé" é um recurso imediato para a propagação das ideologias religiosas, recurso que é conhecido como Televangelismo, que segundo Cunha (2012) é um fenômeno que pode ser explicado da seguinte maneira:

Tal ideia nasceu, evidentemente, no coração do capitalismo, os Estados Unidos, no início do século XX. O pai dessa fé sonante é o americano Essek William Kenyon (1867-1948), um evangelista de origem metodista nascido em Saratoga, Estado de Nova York. Descobriu o milagre do rádio e plantou ali a sua igreja no ar, a ancestral eletrônica dos R.R. Soares e Malafaias da vida. Espalhou então aos quatro ventos o lema que explica as benesses divinas da fartura: "O que eu confesso, eu possuo". (TEMPLOS ELETRÔNICOS - OS ESPARTALHÕES DA FÉ)

Portanto, o pioneirismo americano desenvolvido no rádio logo propiciou a ascensão religiosa também à televisão, cujo potencial de alcance é exponencial, visto seu caráter como "meio de comunicação de massa". Não demorou muito para isto chegar ao Brasil, tendo início na década de 1990, conforme Lima (2005) que afirma que a referida tendência foi simbolizada pela compra da TV Record pela Igreja Universal do Reino de Deus, bem como da entrada em funcionamento da Rede Vida de Televisão, ligada à Igreja Católica, em 1995.

O maior avanço é o das igrejas evangélicas neopentecostais, embora, historicamente, a Igreja Católica seja o maior concessionário de emissoras de rádio no Brasil. Em alguns casos, a presença das igrejas como concessionárias é bastante evidente, 
como, por exemplo, na programação vespertina dos canais da TV aberta, tanto em VHF como em UHF. (LIMA, 2011, P. 30)

Portanto, a partir desses eventos, muitas outras denominações cristãs compraram emissoras ou então alugaram espaços para "transmitir" sua evangelização aumentando a representatividade destes grupos nos espaços midiáticos brasileiros, buscando atrair, pelos recortes discursivos de maneira convincente e persuasiva.

\section{A DENOMINAÇÃo IURD E A PRÁTICA DO TELEVANGELISMO}

Nas últimas décadas o movimento neopentecostal brasileiro tem crescido vertiginosamente, decorrente das mudanças sociais que vêm ocorrendo. Portanto, os antigos comportamentos característicos dos pentecostais entre os quais a rigidez nos costumes e na interpretação do evangelho, foram sendo substituídos por uma flexibilização teológica e comportamental, como destaca Nascimento, "De modo que seus fiéis foram liberados para vestir roupas da moda, usar cosméticos e demais produtos de embelezamento, frequentar praias, piscinas, cinemas, teatros, torcer por times de futebol, praticar esportes variados, assistir televisão e vídeos, tocar e ouvir diferentes ritmos musicais" (2012, p. 53).

Entre as denominações que assumiram está roupagem, está a Igreja Universal do Reino de Deus (IURD) que se transformou na mais conhecida e influente instituição religiosa do Brasil. Além da atuação política, a IURD desfruta de um verdadeiro império midiático que incluem emissoras de televisão, rádio, jornais, revistas e sites, estas estão submetidas às ordens da instituição e de seu líder máximo.

Esta estratégica relação com mídia proporcionou a IURD uma rápida propagação de seus princípios religiosos, resultando em um aumento considerável de fiéis. Este fenômeno só se tornou possível a partir do "Televangelismo Iurdiano", tornando-se um traço característico da denominação na consolidação da sua teologia.

\footnotetext{
A IRUD através da rede Record utiliza sua verdade bíblica com o intuito de aumentar ainda mais a credibilidade de sua teologia. Ao longo dos programas e cultos os pastores pregam que só é feliz quem faz parte da IURD. As pessoas aparecem dando testemunhos, dizendo-se livres dos mais diversos problemas, sejam eles emocionais ou até mesmo financeiros. (NASCIMENTO. 2012, p. 69)
}

Portanto, sob este palanque propagandístico, a IURD consegue atingir uma grande massa de indivíduos das mais diversas localidades geográficas, levando para estes locais a sua mensagem e o seu proselitismo religioso. Este evangelismo eletrônico se destaca não somente por enfatizar a figura do pastor ou bispo, mas também por destacar a imagem dos fiéis, 
principalmente durante a exposição dos testemunhos dos milagres alcançados, os quais servem de vitrine para a denominação, com o objetivo de ratificar ao telespectador o poder imensurável de Deus e da igreja no combate as trevas que buscam a destruição de toda a criação divina. Através deste discurso cruzadístico contra as forças malignas, a IURD procura ganhar novos adeptos oferecendo-lhes a esperança de cura e de prosperidade financeira, assim como a salvação eterna, tudo isso difundido através de programas que expõem dramas individuais ou coletivos, os quais foram superados pela força da fé.

Assim, esta "espetacularização" da fé, feita em escala industrial pelos programas televangelísticos da IURD está alicerçada a partir de uma lógica de consumo, na qual os fiéis internalizam modelos sociais a serem seguidos. Desse modo, verifica-se uma associação entre a fé "iurdana" e o acesso ao consumo no qual as pessoas convertidas crêem, que a conquista de bens materiais aliadas a ascensão social evidencia ação do divino em suas vidas. Isso mostra "como as camadas populares convertidas ao pentecostalismo veem representados seus desejos de participar do processo simbólico que reafirma os poderes de uma sociedade que reifica a cultura do consumo" (NASCIMENTO, 2012, p. 73).

Desse modo, é possível perceber na programação religiosa pertencente a IURD, uma constante construção de sua identidade religiosa. Contudo, adaptando a sua mensagem à vida material e cultural de seus fiéis, a fim de fornecer explicações sobre como viver e justificar o seu atual status social. Dessa forma, fica evidente como a IURD pode unir em seu âmago, através do avanço tecnológico, a propaganda religiosa, presente nos programas televangélicos, e as necessidades do mercado. Isso constitui uma nova forma de expansão de suas doutrinas, que a cada instante dispõe de espaço na emissora de televisão Rede Record, através de vários programas, entre eles está o programa "Fala que Eu Te Escuto", se solidificando cada vez mais e, ao mesmo tempo, buscando a adesão de novos adeptos.

\section{O PROGRAMA DE TELEVISÃo "FALA QUE EU TE ESCUTO" COMO MECANISMO DE EVANGELIZAÇÃO}

Dentre todos os programas televangélicos desenvolvidos pela IURD, o programa "Fala que Eu Te Escuto" apresenta algumas peculiaridades pouco comuns no que tange ao gênero. Portanto, a sua excepcionalidade no cenário midiático evangélico torna-o um fenômeno sociorreligioso fundamental para a compreensão do pensamento "iurdiano", particularmente com a apreensão dos mecanismos de evangelização utilizados pelo mesmo. Exibido durante as madrugadas, o programa "Fala que Eu Te Escuto" apresenta uma estrutura muito semelhante aos programas não religiosos apresentados em outras emissoras de televisão, 
muito embora "a estrutura do programa seja quase sempre a mesma, isto é, a primeira parte contendo mais ou menos de 25 a 30 minutos para as reportagens, segunda para a participação dos fiéis (em torno de 25 minutos), momento de oração e a despedida" (NASCIMENTO, 2012, P. 75).

Criado no final dos anos 90, o programa "Fala que Eu Te Escuto", inicialmente, se dedicava a exposição de temas religiosos. Entretanto paulatinamente o programa foi aos poucos assimilando características jornalísticas, abordando temas relacionados à violência, estética, drogas, prostituição, mídias sociais e outros.

Esta forma de abordagem, característica dos programas jornalísticos e de entretenimento, é uma estratégia para atribuir credibilidade ao programa e suscitar um maior interesse por parte dos telespectadores. Portanto, ao adotar está postura, a IURD, busca transparecer um suposto discurso de "neutralidade". Contudo, o programa se utiliza do discurso proselitista neopentecostal com o intuito de difundir os seus princípios de fé. Portanto, a principal finalidade do programa "fala que eu te escuto" não seria converter, mas atrair os telespectadores para o seu estabelecimento religioso.

É no interior dos templos que a pregação ou a oferta mágico-religiosa da igreja pode se tornar plausível, isto é, romper o ceticismo e barreiras que impeçam o virtual adepto de se entregar a Jesus, mudar de religião e de se manter na nova comunidade religiosa. (NASCIMENTO, 2012, p, 78)

Logo ao examinar o conteúdo e a estrutura do programa "Fala que Eu Te Escuto" percebe-se como se estabelecem os mecanismos de evangelização direcionados aos telespectadores, a partir das problemáticas contidas no cotidiano social, promovendo formas de convencimento sobre uma nova existência onde esses problemas deixam de existir, desde que mantenha a sua fé inabalável em Deus, com a mediação da igreja.

\section{AS TEMÁTICAS SOCIAIS APRESENTADAS NO PROGRAMA "FALA QUE EU TE ESCUTO” E AS SUAS RELAÇÕES COM AS CONCEPÇÕES DA IURD}

Um traço marcante do programa "Fala que Eu Te Escuto" é a exibição de reportagem no início da atração. Já os temas exibidos são os mais variados possíveis, os quais estão relacionados geralmente a problemas de natureza social, como a violência doméstica, problemas financeiros, crises de relacionamento, sexualidade, estética, comportamentos antissociais, entre outros. O programa adota uma dinâmica semelhante aos talk shows 
americanos, onde o apresentador e um grupo de convidados, geralmente especialistas, discutem o tema pautado.

Este formato do programa, apesar de controverso, tem obtido significativos resultados em audiência, no aumento do reconhecimento da instituição e das suas principais ideias no cenário nacional.

Ao discutir sobre essas práticas é comum encontrar no programa a participação de telespectadores via telefone, Twitter, Facebook, e/ou WhatsApp, que interagem e expõe suas opiniões acerca do assunto discutido. Assim, a IURD busca de modo estratégico através de seus pastores e bispos, envolver seus telespectadores, de forma a criar uma identificação com os problemas apresentados, e assim, sem que percebam, envolvê-los em conjunto de crenças.

\footnotetext{
Através dos testemunhos apresentados procura-se levar aquele espectador a pensar que através da IURD é possível ter uma vida feliz novamente, que a participação da "Terapia do Amor" em qualquer templo da IURD num sábado à noite que, diga-se de passagem, foi uma escolha estratégica em relação ao dia, porque é neste dia que as pessoas costumam sair para passear, ir ao cinema, namorar e etc. Mas que está sozinho por algum motivo e com o coração partido encontra consolo e esperança neste ritual. (NASCIMENTO, 2012, p, 86)
}

Portanto, ao analisar o conteúdo do programa de televisão destacado, percebe-se o quanto ele tenta ser abrangente e manter-se inteirado quanto aos acontecimentos do cotidiano dos seus telespectadores, para que a mensagens televangelísticas "iurdianas" alcancem o maior número de pessoas possíveis, sem que para isso precise cair nos clichês televangelistas tradicionais. Assim, partindo de temáticas sociais dos indivíduos, a denominação IURD procura internalizar em seus telespectadores a sua forma de ver o mundo, aumentando de maneira preponderante o seu contingente de fiéis.

\section{MÍDIA, EVANGELIZAÇÃo E AS PRÁTICAS DA IURD}

No processo de midiatização se tem uma forma peculiar de interação, entre tecnologia e o meio social, sendo que a mediação entre esses dois aspectos é feita pelo processo comunicacional, onde se tem as construções de sentidos por intermédio da linguagem, imagem e os discursos. Assumindo a mídia como um meio de interação de referência na sociedade atual, principalmente no que tange a construção de sentidos, pode-se considerar que a própria organização social se estabelece a partir deste meio (Braga, 2006 apud Grohmann; Mauro, 2015, p. 249). Esta organização se firma nos ângulos da realidade que a mídia se propõe a apresentar. Segundo Bourdieu (1997), as percepções que os indivíduos possuem a 
respeito da realidade a partir da mídia são, na verdade, recortes que são apresentados como se referindo ao todo real. Com este trabalho de recorte do real através do qual não é possível ter a visão da totalidade, a mesma impõe suas visões de mundo e controla as ações dos indivíduos, sendo isto característico de seu poder e "violência simbólica". Este conceito trabalhado por Bourdieu tem como fundamento a cumplicidade entre os envolvidos na violência, os legitimadores da mesma e os oprimidos por ela.

O programa "Fala que Eu Te Escuto", através dos temas que são apresentados, se utiliza de recortes de determinados aspectos da realidade social para propagar suas mensagens religiosas. Porém, está propagação atualmente, através do programa, não perpassa totalmente a abordagem teológica - o que não é tido como adequado ao mundo do entretenimento e dificilmente é capaz de gerar grandes audiências. De forma geral, os temas tratam dos problemas cotidianos das pessoas, como os já citados programas que abordaram a questão do "Divórcio" e do "Baile Funk", assim como também, os que trabalharam problemas do vício em drogas, da prostituição, os perigos das redes sociais, etc. Observa-se que aos temas apresentados lhes são exagerados a importância, não que não sejam assuntos importantes a serem tratados, mas a forma como são apresentados através de imagens que, comumente, exprimem profunda tristeza, dos testemunhos de pessoas que enfrentam os problemas destacados e da linguagem utilizada pelo apresentador, tem-se os elementos pertinentes para a instituição religiosa propagar seu discurso. Este exagero no recorte de determinado aspecto social é uma prática comum no âmbito televisivo, levando-se em consideração que "a televisão convida à dramatização" (Bourdieu, 1997, p. 25, de quem é o destaque?). A dramatização é importante porque é através dela que a disseminação de determinado discurso se torna mais eficaz. Logo, a utilização dos problemas do cotidiano pela Igreja Universal do Reino de Deus (IURD) em seu programa gera um processo de identificação do telespectador que se intensifica com a abertura de espaços para debates, questionamentos, etc. Esta é, normalmente, a proposta dos ditos programas-realidade que tem por finalidade trabalhar midiaticamente os sofrimentos do cotidiano.

Na medida em que aborda temas muito caros a muitos brasileiros, o programa acaba estimulando a participação do público, que se dá por meio de um quadro chamado "o povo fala", no qual as opiniões de outras pessoas são ouvidas por meio de enquetes nas quais as pessoas podem escolher o tema, o que sem dúvida instiga os telespectadores, pois muitos desses temas são bastante polêmicos. Outra forma de participar do programa é por meio de telefonemas, e-mails e Skype, onde o telespectador pode conversar ao vivo com o bispo ou com pastor. Essa forma de conduzir o programa, permite a interação entre diversos tipos de 
público, não havendo uma uniformidade entre aqueles que participam. Esse recurso tem como finalidade última, como todo programa televangélico, atingir o maior número de pessoas e, quem sabe, convertê-las.

Os indivíduos constroem suas identidades a partir de valores culturais e dos artefatos simbólicos social e historicamente disponíveis. Não é diferente com a identidade religiosa. Mais do que mero resultado de condições concretas de materialidades presentes nas vidas de indivíduos e grupos, a autopercepção religiosa decorre, sobretudo, de um sentimento de identificação com um discurso (LEAL, 2008, p.98).

O evangelismo praticado pela IURD, a partir de seu programa "Fala que $\mathrm{Eu} \mathrm{Te}$ Escuto", busca a identificação do fiel ou não fiel com as problemáticas levantadas e oferece, em contrapartida, sua mensagem religiosa como subterfúgio para os problemas. Esse duplo da problemática e da mensagem presente em seu "discurso religioso espetacular" se apresenta como um grande atrativo, levando-se em consideração as dificuldades que cotidianamente os indivíduos precisam enfrentar no meio social. Desta forma, a visão de mundo da Igreja é exposta e sua ampla aceitação por parte dos telespectadores do programa, consoante as questões pontuadas, perpassa pela apresentação midiática que a instituição religiosa faz das questões sociais, estando sob a interação fundamentada na relação entre as tecnologias e os discursos e o meio social que o conceito de midiatização, trabalhado neste artigo, propõe.

\section{CONCLUSÃO}

$\mathrm{Na}$ atualidade o campo midiático, a partir de mecanismos que se mostram hábeis no sentido de controlar, ou mobilizar, as vontades e sentimentos dos indivíduos, conforme o que é conveniente aos seus interesses e também renda pontos no Ibope (popularidade). Isto expressa seu caráter de dominação, na medida em que suas percepções de realidade são facilmente aceitas e dificilmente se tem a preocupação em questionar as posturas que a mídia assume diante de determinada temática.

Neste aspecto, essa dominação se caracteriza como carismática, uma relação entre os fiéis e o líder religioso, como expressado pela tipologia de Max Weber:

Dominação carismática em virtude da devoção afetiva à pessoa do senhor e a seus dotes sobrenaturais (carisma) e, particularmente: a faculdades mágicas revelações ou heroísmo, poder intelectual ou de oratória. O sempre novo, o extracotidiano, o inaudito e o arrebatamento emotivo que provocam constituem a fonte da devoção 
pessoal. Seus tipos mais puros são a dominação do profeta, do herói guerreiro e do grande demagogo. A associação dominante é de caráter comunitário, na comunidade ou séquito. O tipo que manda é o líder (...). O quadro administrativo é escolhido segundo seu carisma e vocação pessoais e não devido à sua qualificação profissional (...) falta aqui o conceito racional de competência assim como o estamental de privilégio (...). A administração (...) carece de qualquer orientação dada por regras, sejam elas estatuídas ou tradicionais. São características dela (...) a revelação ou a criação momentânea, a ação e o exemplo, as decisões particulares, ou seja, em qualquer caso (...) o irracional. (WEBER, 2001; p.134-5)

Assim, descrevemos em um primeiro momento o processo de midiatização da sociedade moderna, e de como isso trouxe mudanças significativas no modo como as pessoas se relacionam e também constroem as suas identidades. Esse processo trouxe uma alteração no modo como a religião, em especial o segmento neopentecostal se adaptou e passou a fazer uso desses mecanismos com o intuito de espalhar a sua mensagem religiosa. Dentro desse panorama encontramos o televangelismo iurdiano, representado aqui pelo programa "Fala que Eu Te Escuto" que, ao longo dos anos, tem sido o seu principal produto religioso, e que se destaca pela criatividade e versatilidade na sua evangelização. Outro traço que marca esse segmento está na sua teologia da prosperidade que marca uma transformação importante, já que agora não só as preocupações do mundo espiritual devem estar presentes, mais também as preocupações terrenas, pois é pelas manifestações de Deus na vida do fiel que se faz possível saber qual será o seu destino após a morte.

Assim sendo, os resultados obtidos com essa investigação podem constatar que o programa "Fala que Eu Te Escuto" é o principal front religioso da Igreja Universal do Reino de Deus, tendo como uma das suas principais finalidades servir como "isca", atrativo, para que os espectadores conheçam as doutrinas da igreja e posteriormente tenham a curiosidade de frequentá-la efetivamente para, em seguida, a ela se converterem.

\section{REFERÊNCIAS}

BOURDIEU, Pierre. Sobre a televisão. Rio de Janeiro: Jorge Zahar Ed., 1997.

CUNHA, Luiz Cláudio. Templos Eletrônicos - Os espertalhões da fé. Observatório da Imprensa, 10 Jan. 2012.

FAIRCLOUGH, Norman. Discurso e Mudança Social. Editora Universidade de Brasília. Brasilia, 2001.

FRESTON, PAUL. Protestantes e política no Brasil: da constituinte ao impeachment. Tese de doutorado, Departamento de Ciências Sociais do Instituto de Filosofia e Ciências Humanas da Universidade Estadual de Campinas, Campinas, 1994. 
GASPARETTO, P. R. A Complexidade do Conceito de Midiatização e a Construção de Novas Comunidades de Pertencimento. In: II Colóquio Semiótica das Mídias, ISSN: 23179147, 2013, Japaratinga - Alagoas.

Grohmann, R; MAURO, R. O Potencial Teórico do Conceito de Midiatização e os Estudos Sobre Classes Sociais na Comunicação. Novos Olhares, São Paulo, v. 4, n. 1, p. 246-257, $1^{\circ}$ semestre de 2015.

LEAL, Paulo Roberto Figueira. Jornalismo e construção da identidade espírita: os enquadramentos sobre o médium Zé Arigó nos periódicos "O Dia" e "Jornal do Brasill". In:

LIMA, Venício Artur de. Regulação das Comunicações: História, Poder e Direitos. São Paulo: Paulus, 2011.

LIMA, Venício Artur de. Mídia: Teoria e Política. São Paulo. Editora Fundação Perseu Abramo, 2005.

MCLUHAN, Marshall. Os Meios de Comunicação Como Extensões do Homem. São Paulo: Cultrix, 2007.

NASCIMENTO, Cleoneide Moura. "Fala que eu te escuto" Espetáculo Universal da Fé. Tese de qualificação de doutorado: programa de Pós-Graduação em sociologia do centro de ciências humanas, letras e arte. UFPB, 2012.

OLIVEIRA, Derli Machado de. Entre a Fé, a Obra Social e a Publicidade: Uma Análise Crítica do Discurso da Responsabilidade Social da Igreja Universal do Reino de Deus. Tese de Doutorado: Programa de Pós-Graduação em Estudos da Linguagem. UFRN, 2013.

SGORLA, Fabiane. Discutindo o "Processo de Midiatização". Mediação, Belo Horizonte, v. 9, n. 8, p. 59-68, jan/jun 2009.

PASSOS, João Décio. Pentecostais: Origens e Começos, São Paulo, Paulinas, 2005.

PATRIOTA, Karla Regina Macena Pereira. Fala que eu te escuto: $\mathrm{Na}$ Era do Entretenimento, a Doutrina é o Espetáculo. (encipecom.metodista.br)

WEBER, Max. Textos Coligidos. São Paulo: Ática, 2001. 